\title{
http://bjas.journals.ekb.eg \\ Comparative Study between Total Mesocolic Exesion Versus Conventional Right Hemicolectomy in management of Tumors of the Right Colon
}

\author{
A.A.Yousef, M.M.Mohamed, A.M.Zidan and A.M.Abostate \\ General Surgery Dept., Faculty of Medicine, Benha Univ., Benha, Egypt \\ E-Mail: A.Abostate@gmail.com
}

\begin{abstract}
The essential treatment for colon malignant growth is medical procedure. The piece of the huge inside with malignancy is evacuated, alongside encompassing lymph hubs. Malignancy found in the climbing colon and hepatic flexure, the correct side is evacuated by right hemicolectomy or expanded right hemicolectomy. The idea of complete mesorectal extraction (TME) as proposed by Heald et al. in the mid 80's brought about altogether better oncological results in rectal malignant growth medical procedure. TME likewise raised the issue of better results in colon malignant growth medical procedure, which, up to that point, was not normalized and the reports in the writing showed a lot of heterogeneity and high repeat rates. In 2009 and in corresponding to the TME idea, came the primary report and portrayal of the total mesocolic extraction (CME) with focal vascular ligation (CVL), with very noteworthy oncological results and a general 5-year endurance coming to up to $70 \%$ for stage III colon malignant growth patients. They additionally demonstrated that it is a sheltered and plausible strategy which bears at any rate a similar dreariness and mortality as the "purported" standard technique.CME with CVL comprises of two primary segments. Right off the bat, it focuses on the safeguarding of flawless fasciae of the mesocolon between which pertinent lymph hubs are contained. Also, the vessels that gracefully the tumor colon site must be ligated at their starting point, to be specific at the degree of the unrivaled mesenteric vein for right sided injuries, thusly the nerves of the celiac plexus, which run along the predominant mesenteric supply route, and the hypogastric plexus, which runs on the aorta, individually, are secured, and the evacuation of the total mesocolon and the greatest lymph hub yield is accomplished.
\end{abstract}

\section{Introduction}

Colorectal malignant growth is the seventh commonest disease in Egypt, representing $3.47 \%$ of male tumors and $3 \%$ of female malignancies. The evaluated number of colon malignant growth patients (barring rectal disease) in 2015 was marginally in excess of 3,000. The study of disease transmission of colon malignant growth varies in every nation. There is a lack of studies talking about the conduct of this basic disease in Egypt, the biggest of which is Abou-Zeid et al. in 2002.Two decades have gone since this investigation, as of now a significant change happened in our comprehension of malignancy designs in Egypt, with the distribution of the main national populace based disease library in 2014, and furthermore urbanization and change ways of life ought to have influenced colon malignant growth design [1].

During the 1980s, absolute mesorectal extraction (TME) was introduced by Heald . Premise of TME was the embryological advancement of the rectum, dismemberment with embryological planes of dorsal mesentery yields a perfect example which incorporates all vascular and lymphatic pathways and lymph hubs. This analyzation gives more opportunity to clean circumferential edge .TME changed the rectal disease medical procedure fundamentals and furthermore influenced results. Nearby repeat rates diminished from $30-40 \%$ to $5-15 \%$ by TME unrest [2].

Hohenberger applied TME reasoning for the medical procedure of colon malignant growth. Their examination indicated that instinctive and parietal peritoneum were secured the colon, similar to a sheath and this was comparative with mesorectum life structures by the manner in which they set forward total mesocolic extraction (CME). Hohenberger portrayed a technique for far reaching extraction of all mesocolic tissue that was comparable to right-sided hemicolectomy. The new complete technique varies from the customary careful strategy for the most part attributable to

1. More halfway found extraction of tissue along the tumor-depleting vessels, and in this manner an expanded potential for expulsion of lymph hubs.

2. Increased consideration regarding dismemberment in the embryological planes to encourage evacuation of an unblemished mesocolon [3].

We here quickly depict the careful methods in right-sided hemicolectomy. Besides, we report the lymph hub status saw in the conventional and the thorough examples. Two conventional careful strategies are utilized in right-sided hemicolectomy:

1. Average access ("no touch") (total mesocolic extraction)

2. Sidelong access (customary technique)

In average access, the specialist applies a sidelong draw to the caecum to encourage introduction of the ileocolic vessel. Without assembling the focal structures, the specialist makes the entry point as halfway in the previously mentioned vessel structures as appears to be convenient. These vessels are then segmented as per the rule that any control of the tumor ought to be stayed away from preceding vessel ligature. On the off chance that the specialist chooses to move toward the vessel structures as halfway as could reasonably be expected, the predominant mesenteric vessel ought to be uncovered utilizing a foremost methodology. Such presentation is probably going to bargain protection of an unblemished mesocolon in the focal pieces of the example. Following vessel ligation, the correct portion of the colon is prepared and entrail resection is performed. 
In parallel access, the specialist prepares the correct portion of the colon in the undeveloped planes confronting the retroperitoneal structures (renal belt, duodenum, and pancreas) and afterward continues to cut off the two resection destinations of the colon and the terminal ileum. Next, the mesocolon is cut off, in a $\mathrm{V}$-shape-like design, towards the focal vessel structures, and, at long last, inside resection and ileocolic anastomosis is finished

Complete mesocolic extraction with focal vascular ligation (CME+CVL) has been proposed as a strategy of principal significance for the administration of colon tumors, since it amplifies lymph hub yield and stays away from interference of lymphatic seepage .Impressive results have been accounted for ;nonetheless, direct examinations with the exemplary methodology are missing .In this investigation, the careful and oncologic results of complete mesocolic extraction with focal vascular ligation were contrasted with standard medical procedure for right colon malignancies [4].

\section{Patient and method}

This is prospective controlled study carried out on 60 patients admitted to department of surgery in Banha university from December (2017) to December (2019) and diagnosed as right sided colon cancer. All patients had read and signed informed consents.

The patients are divided into two groups:

1. Group $\mathbf{A}(\mathbf{n}=\mathbf{3 0})$ : underwent medial approach right hemicolectomy

2. Group B $(\mathbf{n}=\mathbf{3 0})$ : underwent lateral approach right hemicolectomy

\section{Inclusion criteria}

1. Patients with primary operable right sided colon cancer

2. patients fit for surgery

\section{Exclusion criteria}

1. Patients with locally advanced or metastatic right sided colon cancer (stage IV).

2. Patients not fit for surgery.

\section{Operative technique}

groupA : (average methodology for right hemicolectomy);

In this gathering, the patient was additionally positioned in a recumbent position, and the activity was acted in a standard way in 7 cluding CME and CVL. A midline entry point around $15-20 \mathrm{~cm}$ was made, and a medial $\neg$ to $\neg$ lateral dismemberment was performed along these lines. The dismemberment began along the unrivaled mesenteric vessels, underneath the third bit of the duodenum.
At first, finding the ileocolic and predominant mesenteric vessel pedicles: The cross over colon and the ileocecal intersection were towed cranially and along the side individually. These withdrawals rose up the base of the mesentery and the correct mesocolon, showing the ileocolic and prevalent mesenteric vessels obviously. Opening the "mesenteric window" and investigating the privilege retrocolic space:

The "mesenteric window" was opened exactly at the mediocre edge of the ileocolic vascular pedicle, which stood apart plainly. The privilege retrocolic space between the mesocolon and the privilege prerenal sash was the characteristic careful arrangement of the all-inclusive right hemicolectomy in which duodenum is recognized and secured. The privilege retrocolic space was expanded along the side and cranially through the "mesenteric window"

Analyzing the gastrocolic tendon and center colic artery:The sub-par some portion of the duodenum was the primary uncovered structure over the span of expanding the privilege retrocolic space cranially, with the uncinate procedure of pancreas uncovered consequently. The correct colic supply route (in the event that it existed) and the gastrocolic venous trunk were then found and skeletonized while dismembering the ventral of the (SMV) caudally to cranially. The gastrocolic venous trunk was depicted as the intersection of the correct colic vein and the privilege gastroepiploic vein $(\mathrm{RGeV})$ depleting into the (SMV) at a normal separation of $2.2 \mathrm{~cm}$ from the second rate pancreatic outskirt. The center colic vessels were the main parts of the predominant mesenteric vessels when they came outside of the pancreatic neck. In our unit, so as to find the center colic vessels, we ordinarily skeletonized the (SMV) cranially and respected the second rate of the pancreatic neck as the anatomical milestone. The correct colic vessels, right gastroepiploic vein, and center colic vessels were isolated at their inceptions individually cautiously. Dismemberment of the lymph hubs and lymphatic tissues at the starting point of these vessels was likewise performed taking the entire lympho vascular tissue inside the example. Analyzation proceeded between the mesocolon and the privilege pre-renal belt all through for security and oncologic quality.

Assembly of the cross over colon and hepatic flexure: The gastrocolic tendon was isolated rightwards close to the more prominent gastric shape outskirt until the hepatocolic tendon was partitioned totally, and afterward the cross over colon and hepatic flexure were prepared. The cross over mesocolon was separated downwards caudally until it joined the arrangement of RRCS analyzed already 


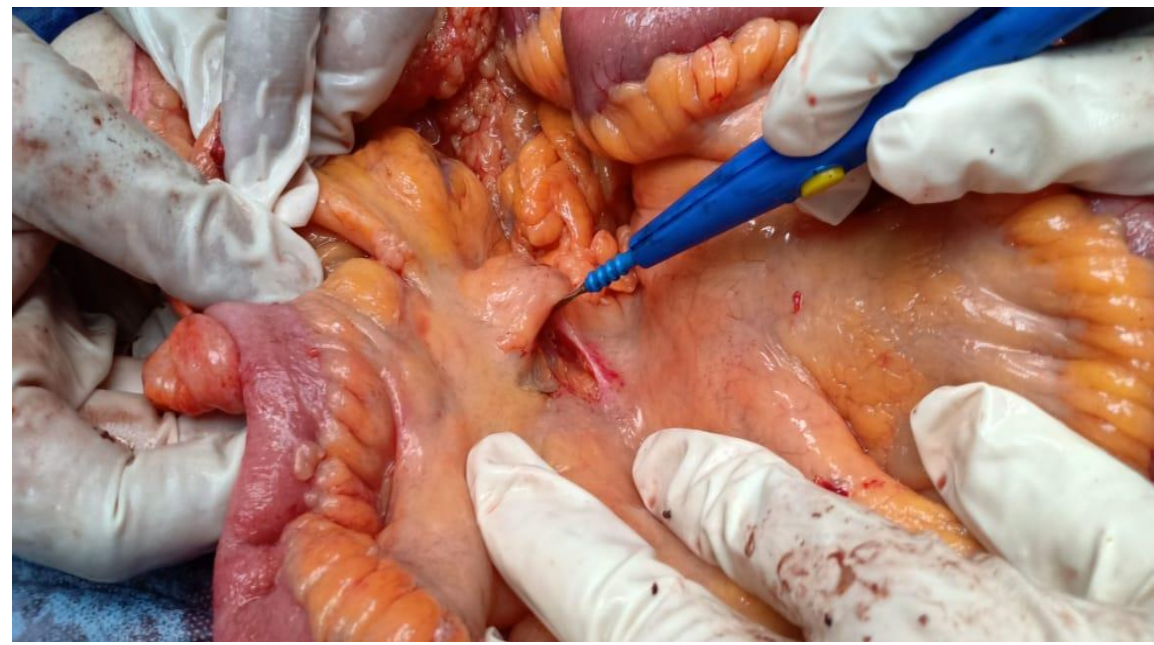

Fig (1) Entering the plane under iliocolic vessels

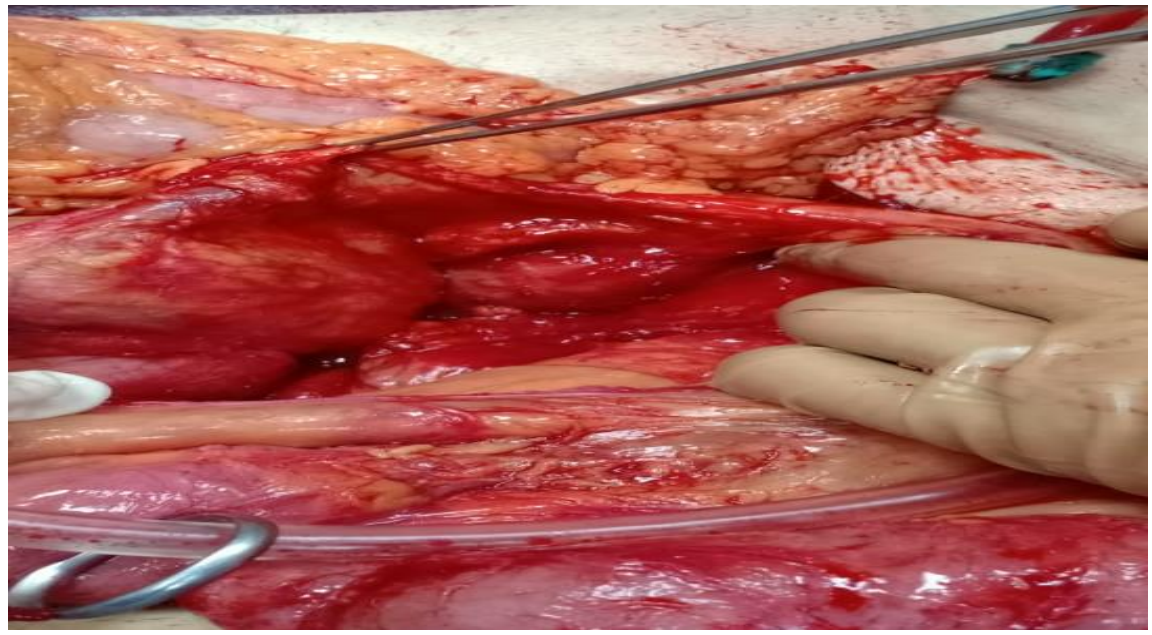

Fig (2) creating the plane under the iliocolic vessels with exposure of the duodenum and head of the pancrease.

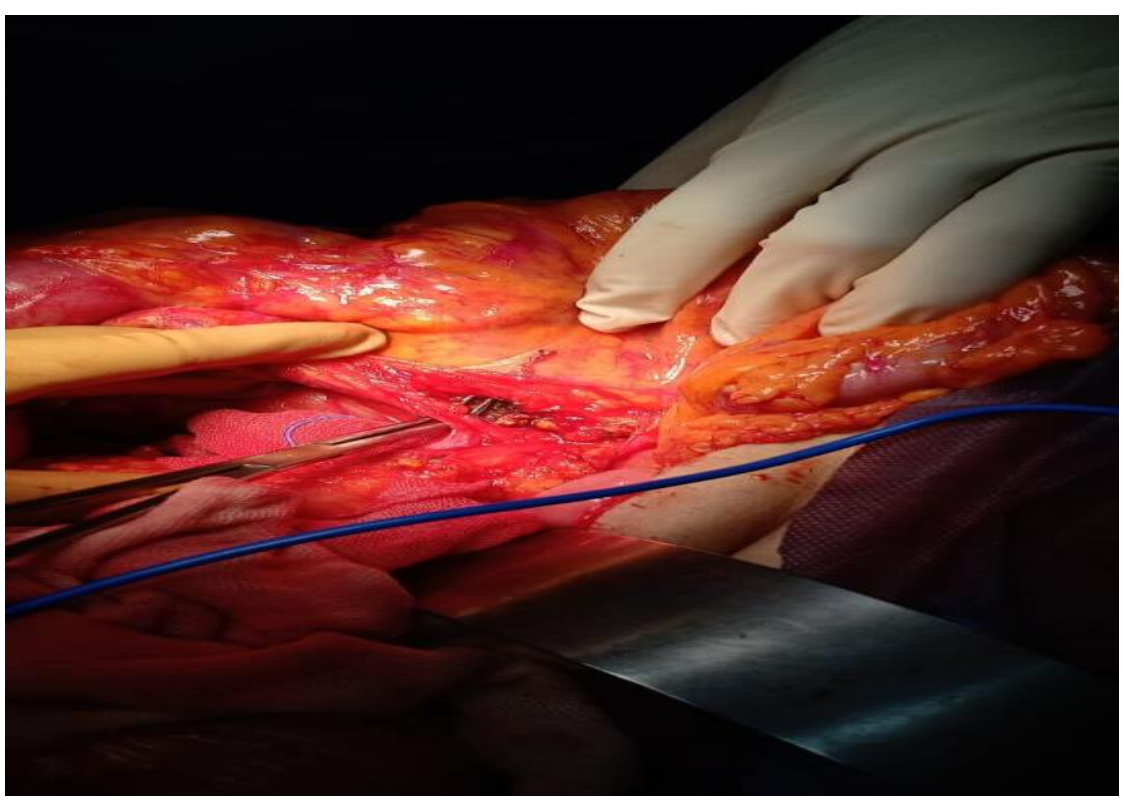

Fig (3) Exposing the ilio colic pedicle to its origin at the superior mesentric axis. 


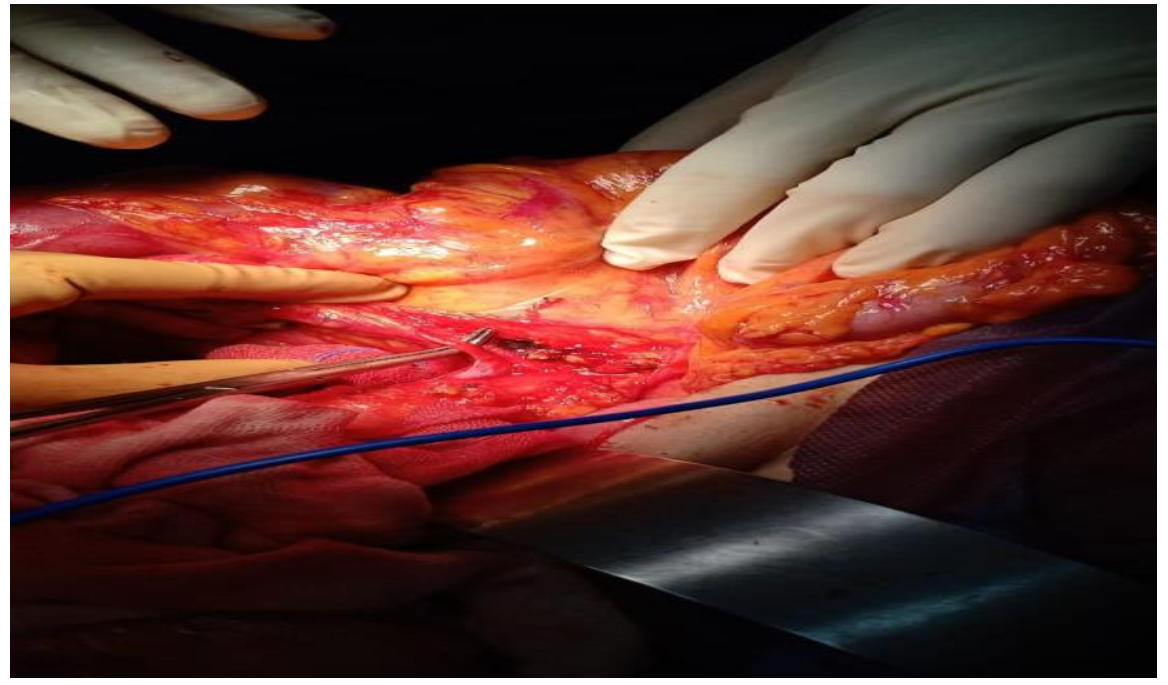

Fig (4) Ligation of iliocolic artery and vein at its origin from the superior mesentric axis

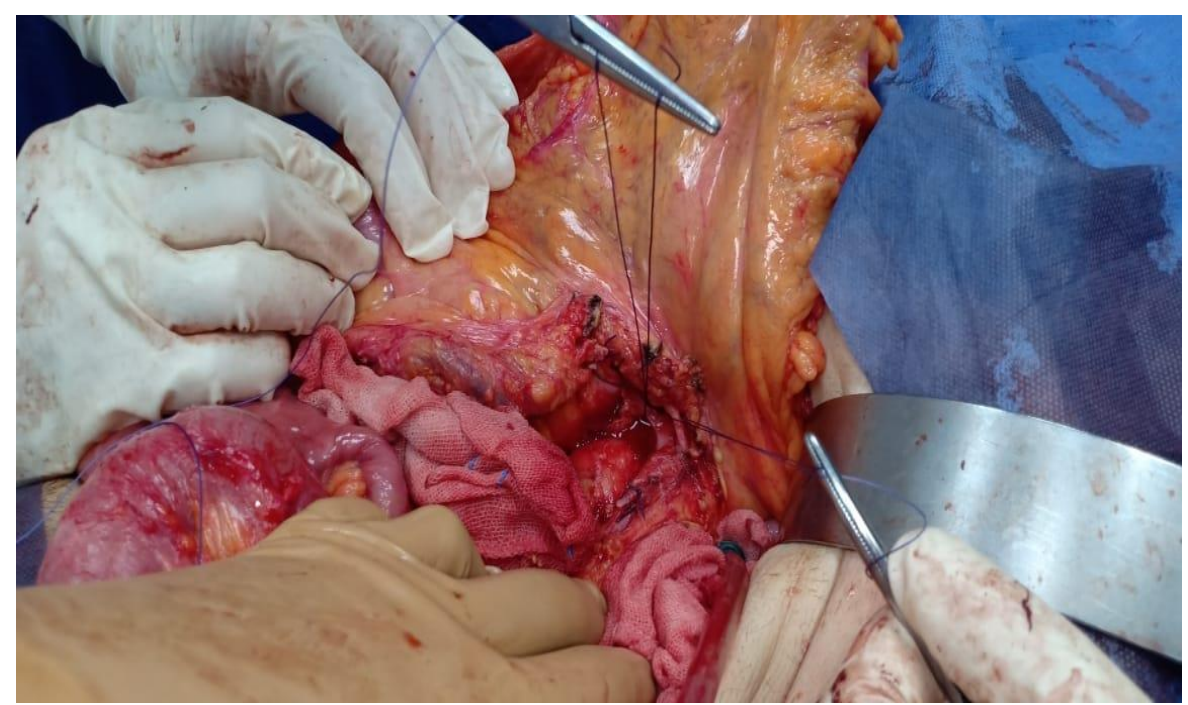

Fig (5) dissection and ligation of middle colic vessels at its origin.

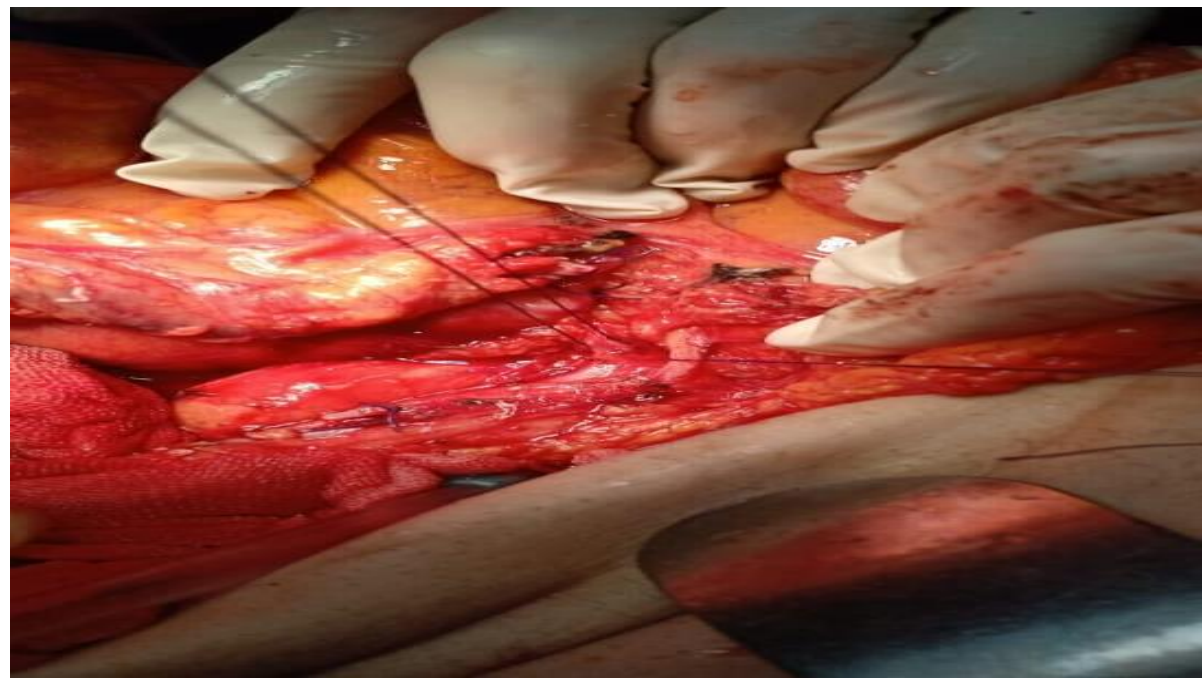

Fig (6) Dissection and ligation of middle colic vessels at its origin 


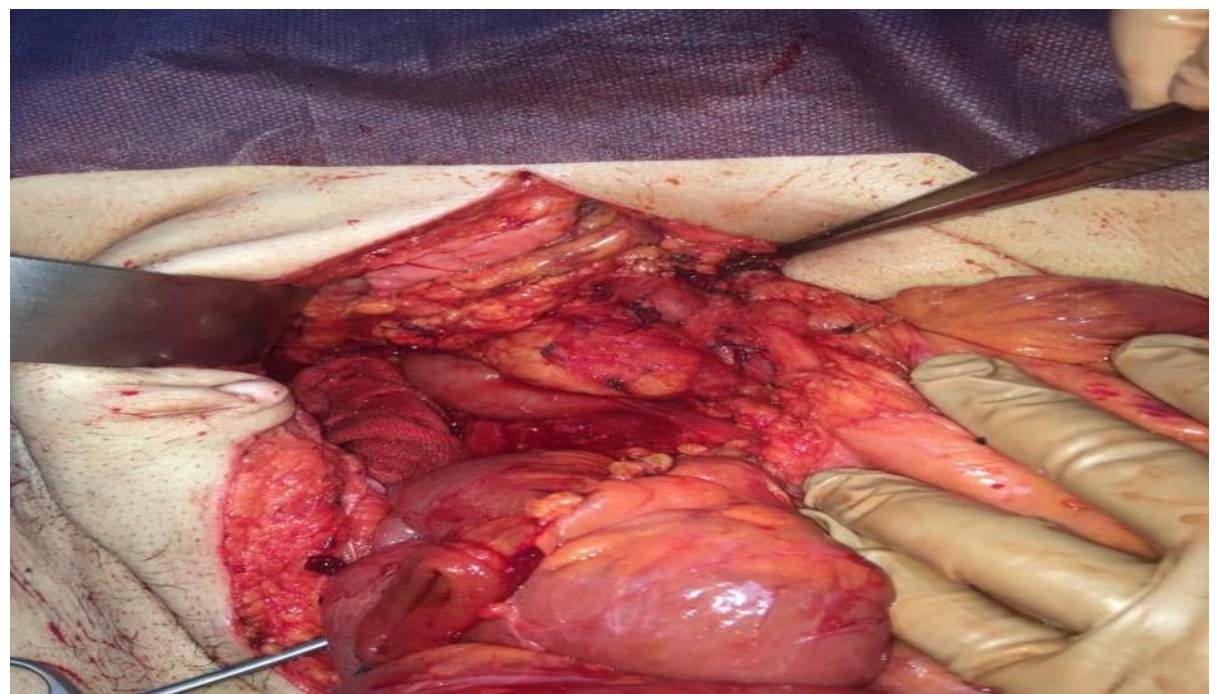

Fig (7) After right colonic resection.

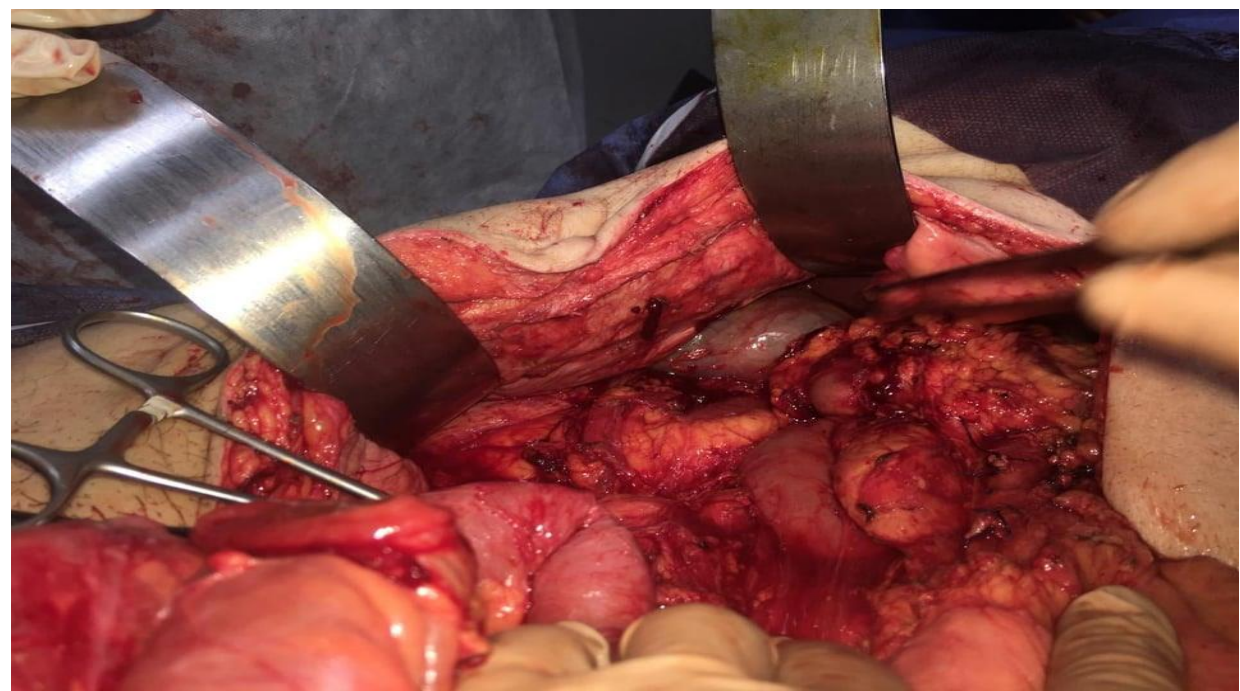

Fig (8) After right colonic resection.

\section{Group B: ( lateral conventional approach for right} hemicolectomy)

The parallel regular methodology began by recognizing the right plane between the gastrocolic tendon and the hidden mesentery of the cross over colon. Beginning from the degree of the antropyloric area and continuing near the colon, the tendon is then separated followed by perception of the second bit of the duodenum.

The peritoneum overlying the hepatic flexure and the privilege phrenocolic tendon is separated, effectively distinguishing the profile of the kidney without entering an off-base plane behind it. The hepatic flexure and the proximal cross over colon are isolated from the foremost surface of the kidney and the duodenum by unpolished dismemberment.

Working from the free horizontal peritoneal edge of the assembled hepatic flexure, the privilege paracolic drain is opened along the climbing colon toward the cecum with protection of the ureter average to the gonadal vessels.

After away from of the correct ureter, the terminal ileum is activated analyzing the peritoneum along the base of the little inside followed by vascular ligation, resection and anastomosis.

\section{Factual examination}

Information was investigated utilizing SPSS 24.0 (IBM SPSS Inc. Armonk, NY, USA). Correlations between bunches were made utilizing chi-square test or fisher's accurate test as proper. Results were extrapolated in box and hair plot. P-esteem $<.05$ was viewed as critical.

Information of all patients were entered tentatively into an electronic databank and applied for relative examination. 


\section{Results}

Table (1) Gender and age distribution of the studied group (60).

\begin{tabular}{|c|c|c|}
\hline & \multicolumn{2}{|c|}{ The studied group (60) } \\
\hline & No & $\%$ \\
\hline \multicolumn{3}{|l|}{ Gender } \\
\hline Male & 36 & 60.0 \\
\hline Female & 24 & 40.0 \\
\hline $\mathbf{M}: \mathbf{F}$ & $3: 2$ & \\
\hline \multicolumn{3}{|l|}{ Age } \\
\hline Mean \pm SD & \multicolumn{2}{|c|}{$64.38 \pm 9.81$} \\
\hline Range & \multicolumn{2}{|c|}{ 49.0-86.0 } \\
\hline
\end{tabular}

Table (2) Comparison between the studied groups according to baseline and tumor characteristics.

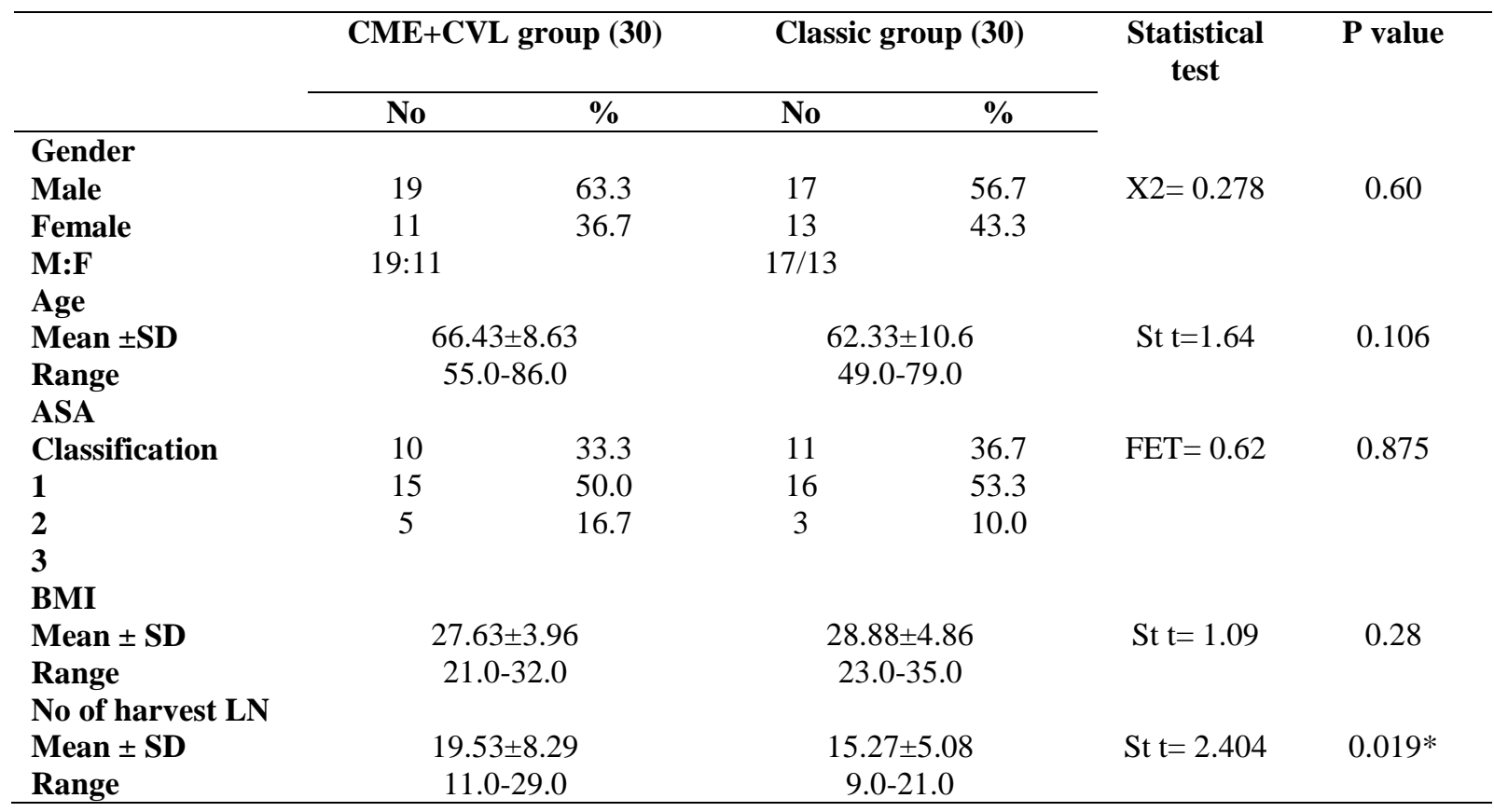

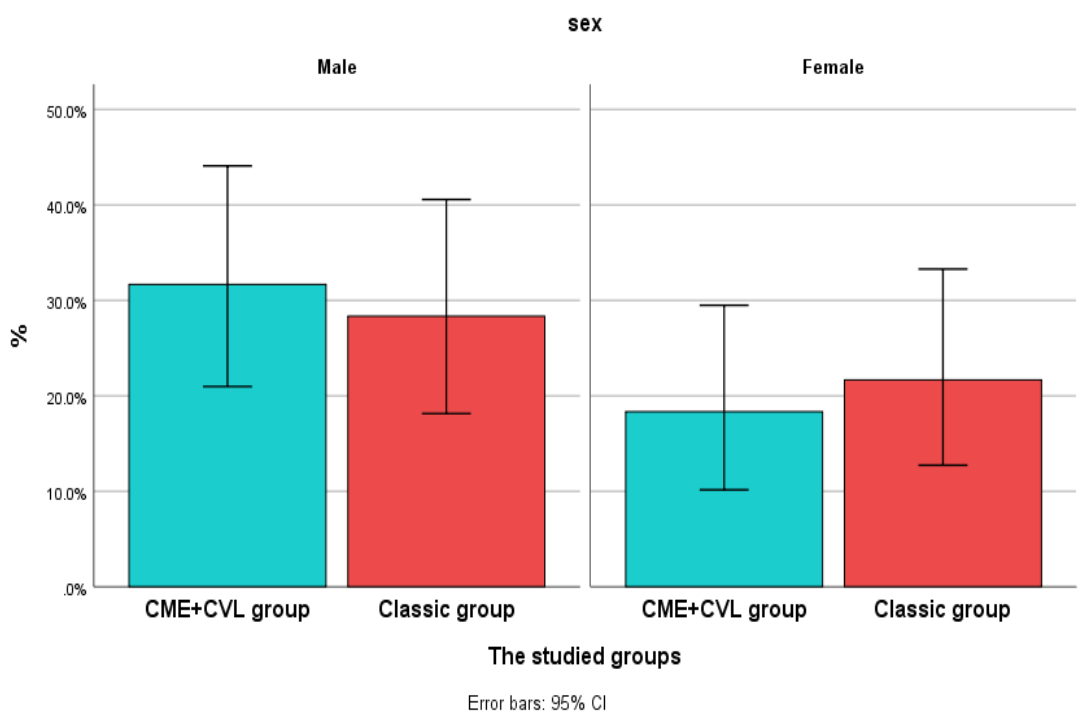

Fig (9) Regarding sex of patients, there is no statistically significant difference between both groups as p value was 0.6 


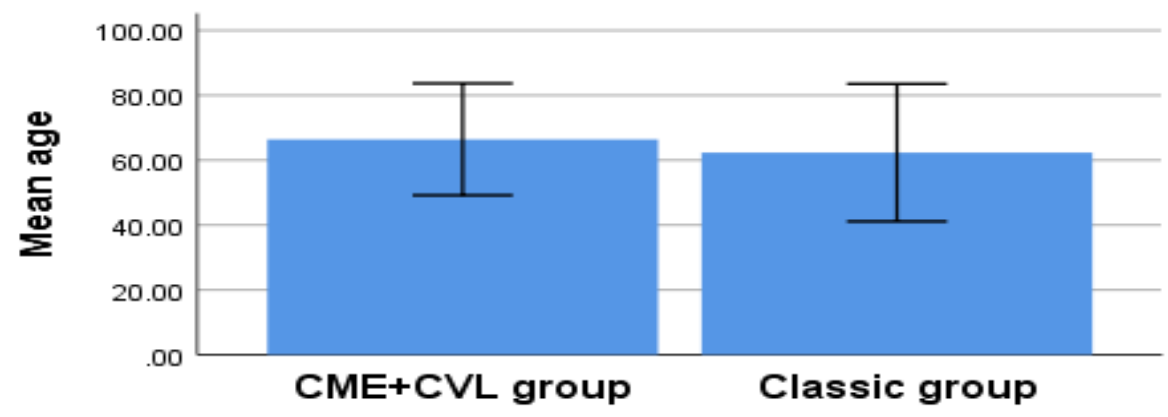

Error bars: +/- $2 \mathrm{SD}$

Fig (10) Regarding the age of the patients, there was no statistically significant difference between both groups regarding age as p value 0.106 .

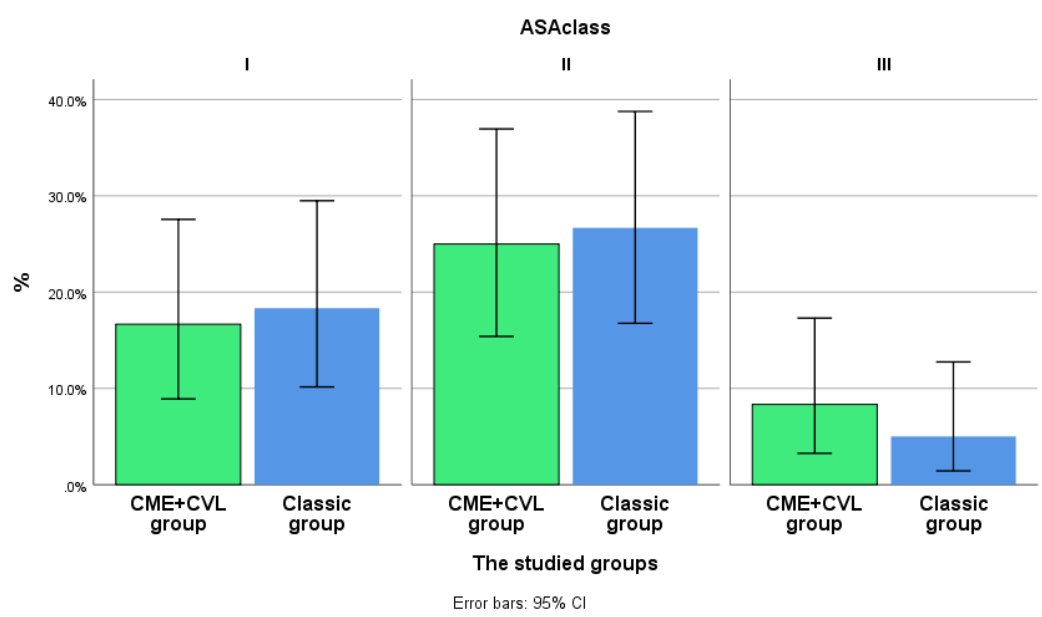

Fig (11) According to ASA classification, there was no statistically significant difference between ASA1, ASA11, and ASA111 in both groups as p value is 0.875 .

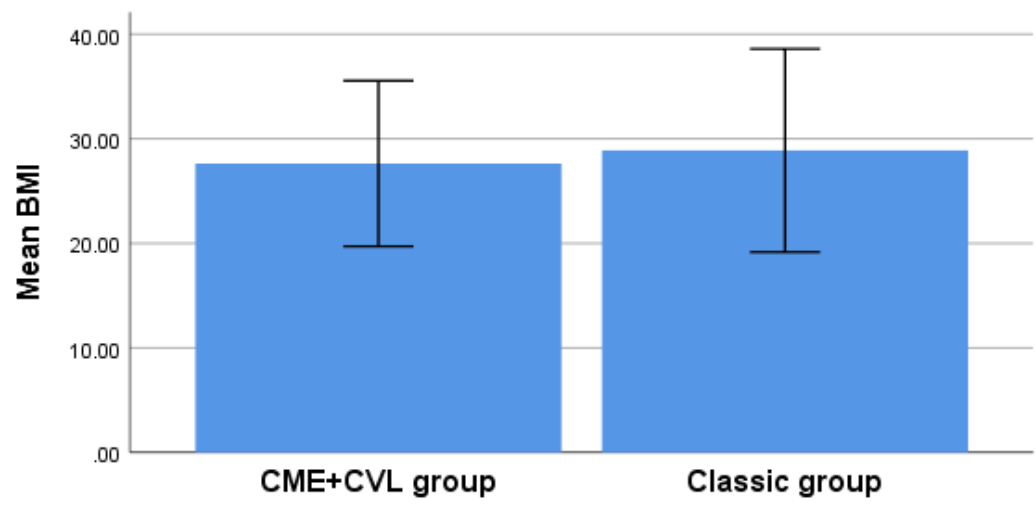

Error bars: $+/-2 \mathrm{SD}$

Fig (12) Regarding the BMI of the patient there was no statistically significant difference between both groups as $\mathrm{P}$ value is 0.28 . 


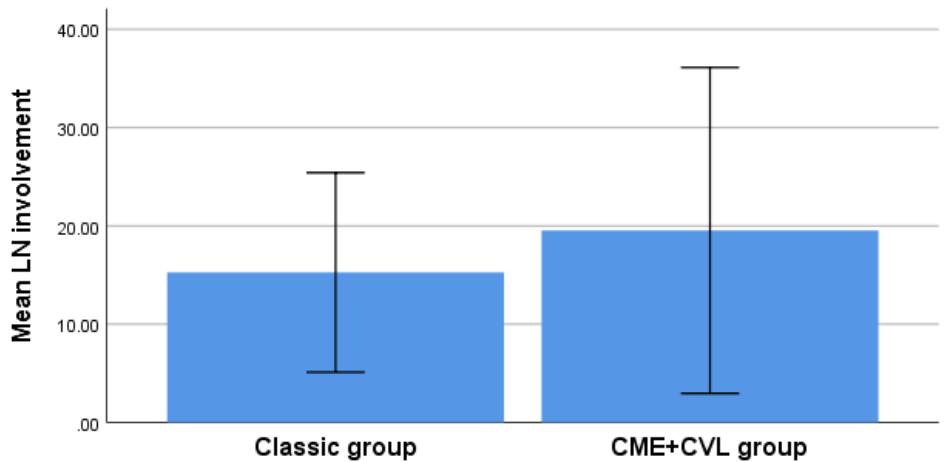

Error bars: +/-2 SD

This table show statistically significant difference between group A and group B regarding number of lymph nodes harvested as $\mathrm{P}$ value is 0.019 .

Table (4) Comparison between the studied groups according to tissue morphometry data.

\begin{tabular}{lcccc}
\hline & $\begin{array}{c}\text { CME+CVL group } \\
(\mathbf{3 0})\end{array}$ & $\begin{array}{c}\text { Classic group } \\
(\mathbf{3 0})\end{array}$ & $\begin{array}{c}\text { Statistical } \\
\text { test (st t) }\end{array}$ & P value \\
\hline $\begin{array}{l}\text { Length of specimens } \\
\text { Mean } \pm \text { SD }\end{array}$ & $28.97 \pm 5.84$ & $22.40 \pm 3.64$ & 5.23 & $<0.001^{* *}$ \\
$\begin{array}{l}\text { Range } \\
\text { Distance from nearest bowel }\end{array}$ & $22.7-34.9$ & $18.6-26.2$ & & \\
$\begin{array}{l}\text { wall to high tie }(\mathbf{m m}) \\
\text { Mean } \pm \text { SD }\end{array}$ & $80.56 \pm 4.30$ & $63.97 \pm 4.18$ & 15.14 & $<0.001^{* *}$ \\
$\begin{array}{l}\text { Range } \\
\text { Distance from tumour to high tie } \\
(\mathbf{m m})\end{array}$ & $76.0-86.0$ & $59.3-68.4$ & & \\
$\begin{array}{l}\text { Mean } \pm \text { SD } \\
\text { Range }\end{array}$ & $117.43 \pm 3.80$ & $83.24 \pm 5.99$ & 26.39 & $<0.001^{* *}$ \\
$\begin{array}{l}\text { Area of mesentery }\left(\mathbf{m m}^{2}\right) \\
\text { Mean } \pm \text { SD } \\
\text { Range }\end{array}$ & $112.0-122.0$ & $77.8-90.2$ & & \\
& & & & \\
& $15963.5 \pm 35.32$ & $10561.0 \pm 34.07$ & 603.0 & $<0.001^{* *}$ \\
\hline
\end{tabular}

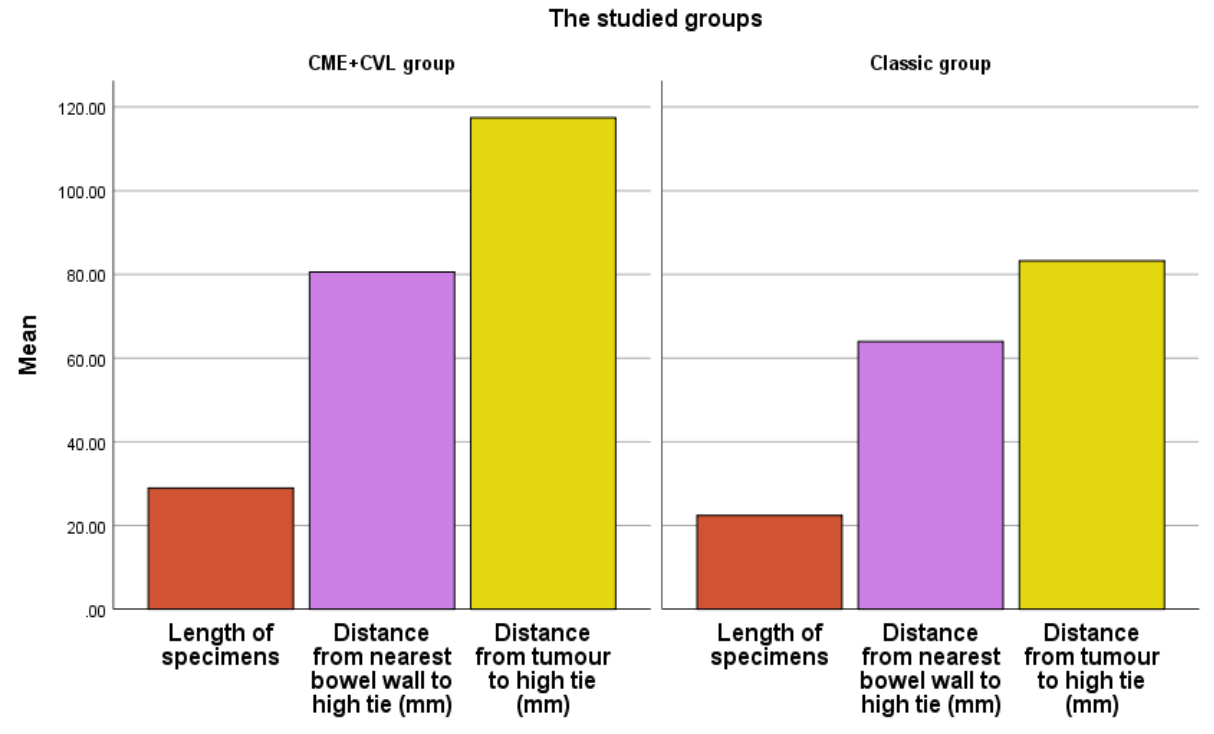




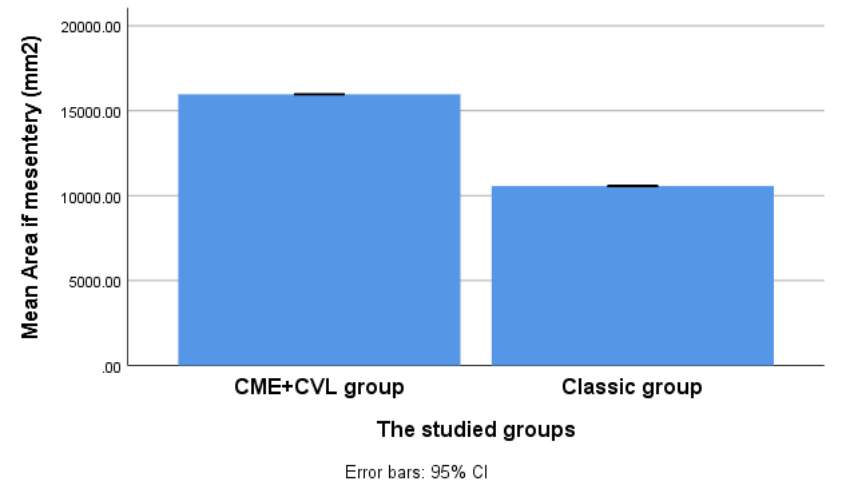

The length of the resected bowel was significantly different between the two groups $(\mathrm{p}<0.001)$.Moreover, a greater area of mesentery was removed with CME and CVL surgery $(\mathrm{p}<0.001)$ and this result, obviously, is attributed to the high tie performed .Patients operated on by CME with CVL displayed significantly greater distance from the tumor to the high vascular tie and the closest bowel wall to the same tie (p value $<0.001$ ).

Table (5) Comparison between the studied groups according to surgical outcome.

\begin{tabular}{|c|c|c|c|c|}
\hline & $\begin{array}{c}\text { CME+CVL group } \\
(\mathbf{3 0})\end{array}$ & Classic group (30) & \multirow[t]{2}{*}{$\begin{array}{c}\text { Statistical } \\
\text { test }\end{array}$} & \multirow[t]{2}{*}{ P value } \\
\hline & No $\%$ & No & & \\
\hline Mortality & 6.7 & 3.3 & $\mathrm{FET}=0.0$ & 1.0 \\
\hline Post-op morbidity & 23.3 & 16.7 & $\mathrm{FET}=0.0$ & 1.0 \\
\hline Anastomotic leakage & 0.0 & 3.3 & & \\
\hline Sepsis & 0.0 & 3.3 & & \\
\hline Bleeding & 3.3 & 6.7 & & \\
\hline Wound infection & 6.7 & 6.7 & & \\
\hline Chyle leakage & 0.0 & 0.0 & & \\
\hline DVT & 3.3 & 0.0 & & \\
\hline Acute myocardial infarction & 3.3 & 0.0 & & \\
\hline Respiratory infection & 3.3 & 0.0 & & \\
\hline Urinary tract infection & 3.3 & 0.0 & & \\
\hline \multicolumn{5}{|l|}{ Operative time (min) } \\
\hline Mean \pm SD & $180.52 \pm 40.72$ & $124.1 \pm 33.96$ & St $t=5.83$ & $<0.001 * *$ \\
\hline Range & $140.0-226.0$ & $90.0-165.0$ & & \\
\hline \multicolumn{5}{|l|}{ Blood loss (ml) } \\
\hline Mean \pm SD & $136.23 \pm 42.36$ & $104.53 \pm 48.46$ & St $\mathrm{t}=2.70$ & $0.009 * *$ \\
\hline Range & $84.0-172.0$ & $50.0-151.0$ & & \\
\hline \multicolumn{5}{|l|}{ Hospital stay (days) } \\
\hline Mean \pm SD & $9.21 \pm 4.37$ & $10.24 \pm 2.01$ & St $\mathrm{t}=1.17$ & 0.25 \\
\hline Range & $4.2-13.1$ & 8.4-12.6 & & \\
\hline
\end{tabular}

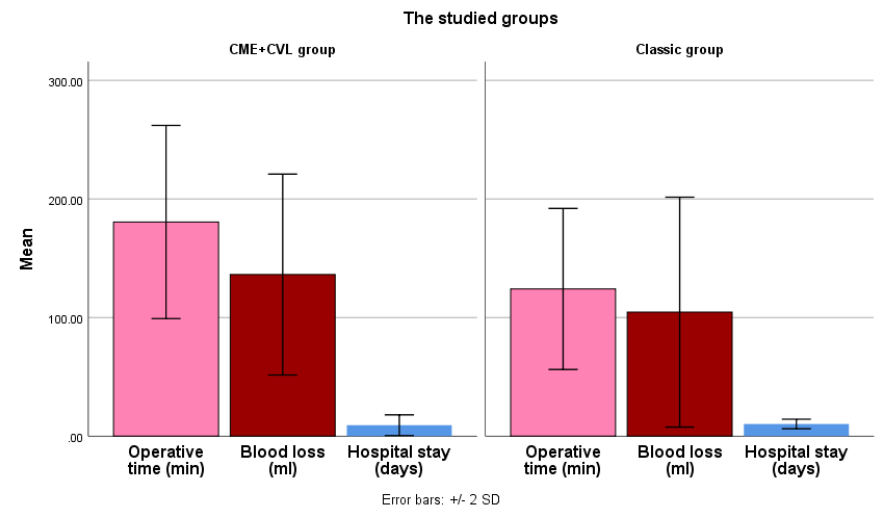

Regarding the operative time and blood loss, there is statistically significant difference between both groups as $\mathrm{p}$ value $(<0.001$ and, 0.009$)$ respectively. 


\section{Discussion}

In this investigation, we tentatively assessed the results of colon disease patients who experienced average methodology right hemicolectomy and sidelong methodology right hemicolectomy. There was no measurable contrast between the 2 gatherings dependent on segment attributes (age, sex diabetes, hypertension) as ( $\mathrm{P}=0.6,0.106,0.875)$ individually.

N.K.Kim et al., [5] show that There were no measurable contrasts in every single coordinating boundary between the two gatherings (P-esteem > $0.05)$.

In this investigation; the Operative time was run from $(180.52 \pm 40.72)$ min with mean worth (140.0226.0) in bunch An, and extended from (124.1 \pm 33.96$)$ min with mean worth (90.0-165) in bunch B with measurably critical distinction between the two gatherings as $\mathrm{p}$ esteem was $<0.001$.

Hyeong et al., [6] demonstrated that the mean usable occasions extended from (156 to 178) minutes, with the employable occasions for CME medical procedure being longer than those for non-CME medical procedure. N.K.Kim et al., [5] additionally demonstrated the comparable outcomes about the employable time. I. Triantafyllidis et al., [7] upheld the idea that the average methodology in right hemicolectomy brought about longer usable time. I. Triantafyllidis et al., [7] additionally appeared $(\mathrm{CME}+\mathrm{CVL})$ bunch was related with fundamentally higher usable time as usable time with complete mesocolic extraction seemed to be $(184 \pm 39)$; nonetheless, employable time with customary right hemicolectomy was $(125 \pm 32)$ with $p$ esteem of $(\mathrm{p}=0.017)$. G.Galizia et al., [8] published outcomes demonstrating that the MA brought about a more drawn out employable time in right hemicolectomy.

As opposed to our outcomes, M.Abdelkhalek et al., [9] reported that The normal length of medical procedure was lower in average methodology in correlation with the conventional sidelong methodology gathering (135minutes versus 180 minutes $),(\mathrm{P}<0.0001)$. This might be credited to the specialists' involvement with following the embryological planes and cautious analyzation of the focal providing veins. The consequences of this examination ought to urge specialists to consider the CME in addition to CVL strategy for the treatment of patients with colon malignant growth since it produces unrivaled examples following the embryological planes, expands the lymph hub yield with a lower $\mathrm{LNR}$, and has adequate bleakness rates.

As to blood misfortune in this examination, blood misfortune was run from $(136.23 \pm 42.36)$ cc with mean worth (84.0-172.0) in bunch An, and extended from (104.53 \pm 48.46$)$ cc with mean worth (50.0-151.0) in bunch B with measurably noteworthy contrast between the two gatherings as $\mathrm{p}$ worth might have been (0.009).

I. Triantafyllidis et al., [7] found that patients in the MA bunch had an altogether more blood misfortune than the LA gathering (MA, $125 \pm 43 \mathrm{~mL}$ ) versus (LA $94 \pm 51 \mathrm{~mL}) ; \mathrm{P}<0.039$ ). (22) uncovered no measurably critical blood misfortune in the MA bunch than LA bunch as $P$ esteem seems to be $(p=0.89)$.(9) detailed that the intraoperative blood misfortune was less in average methodology in contrast with parallel methodology $(105 \mathrm{~mL}$ vs. $200 \mathrm{~mL}, \mathrm{P}<0.0001)$ and it was ascribed to the analyzation in the right careful a vascular planes and the early control of vessels which decrease blood misfortune. In addition, the utilization of consonant and ligasure for speedier control of dying.

Concerning post-usable inconveniences, Although CME with CVL right hemicolectomy is longer and all the more actually testing activity, grimness and mortality were comparative among the two gatherings as $(P$ esteem $=1)$. there were 2 mortality cases following average methodology, one of them was because of aspiratory embolism and the other one was expected to pneumonia.one case experienced traditionalist discharge and earnest investigation was done to control the draining and the patient did well after that. Then again there was one mortality case following the parallel methodology the reason for it was obscure. There was one instance of anastomotic break and was overseen moderately and did well after that.

M.Abdelkhalek et al., [9] said that the quantity of postoperative inconveniences $(n=5)$ was lower in CME contrasted with the customary horizontal gathering, yet the distinction didn't arrive at a factual essentialness $(P=0.702)$. I. Triantafyllidis et al., [7] advocate similar outcomes. Thus, Hyeong et al., [6] said that the postoperative grimness rates extended from $11 \%$ to $28 \%$, however didn't contrast between the CME and the non-CME gatherings. This is upheld additionally by (15). W.Hohenberger et al., [3] said that there is no distinction in horribleness rate between the 2 gatherings. So also,. (4) bolster similar outcomes. (1) said that there is no measurably noteworthy distinction in mortality and grimness between the 2 gatherings. Specifically, C.A.Bertelsen et al., [4] said that the paces of anastomotic spillage were additionally comparative in the two gatherings. (CME medical procedure, $8.6 \%$ and standard surgery,7.6\%). G.Galizia et al., [8] detailed that the paces of anastomotic spillage were additionally comparative in the two gatherings. (CME medical procedure, $4.4 \%$; standard medical procedure, $5.2 \%$ ).

With respect to number of L.N gathered, this examination show measurably huge distinction between bunch An and bunch B in regards to number of lymph hubs reaped as $\mathrm{P}$ esteem seems to be (0.019). G.Galizia,Duck Hyoun et al., [8,10] said that the normal nodal yield of 31.3 is reliable with recently distributed reports of 30 lymph hubs 
with MA gathering and is better than normal yields of less than 20 lymph hubs with LA gathering, and concurred by (11) (14) (12) show the MA bunch had altogether more recovered lymph hubs (MA, 18.8vs. LA, 16.0; $\mathrm{P}=.028$ ) and positive lymph hubs (MA, 3.4vs. LA, 2.2; P= .025 ), and concurred by (13) and (14) as analyzation is reached out to include base of vessels (complete mesocolic extraction) which yield more lymph hubs. N.P.West et al., [11] revealed that examples from colon disease resections from Erlangen, Germany, where CME and focal venous ligation are routinely applied, are all the more frequently in the right anatomical (mesocolic) plane $(92 \%$ versus $40 \%, \mathrm{P}<0.0001)$ and have higher number of lymph hubs reap (middle 30 versus $18, \mathrm{P}<0.0001$ ) contrasted with standard examples from Leeds, United Kingdom. A comparative between institutional examination was per-shaped by similar creators (11) among six Danish emergency clinics where "customary" medical procedure was performed and Hillerod Hospital, where specialists went to a careful instructive preparing program in CME. As envisioned, the resection examples from the last place were portrayed by a bigger mesenteric surface $(144.6 \mathrm{~cm} 2 \mathrm{vs} 87.1 \mathrm{~cm} 2, \mathrm{P}<0.0001)$ and an expanded lymph hub gather (middle 28 versus $18, \mathrm{P}<0.0001)$.

\section{Conclusion}

This examination show that ,there is measurably noteworthy contrast between the two gatherings with respect to usable time, blood misfortune, and oncological security and lymph hub collecting as $\mathrm{p}$ esteem was 0.001 . Average methodology for resection of right side colon malignant growth demonstrated that the average methodology is in fact plausible and safe. In spite of the fact that it was related with a fundamentally higher usable time and more intraoperative blood misfortune in contrast with the sidelong methodology, all activities were fruitful and these variables didn't influence the postoperative course, which was comparable in the two gatherings, in regards to hospitalization .Although CME with CVL right hemi colectomy is longer and all the more actually testing activity, dreariness and mortality were comparative among the two gatherings. Other than the oncologic points of interest of an early vessel division and a "non-contact" analyzation, we feel that the more drawn out the sidelong stomach divider connections of the colon are saved, the better the presentation and the simpler the dismemberment.

\section{References}

[1] A.S.Ibrahim, H.M.Khaled, N.N.Mikhail, H.Baraka, and H.Kamel,Cancer incidence in Egypt: results of the national population-based cancer registry program. J Cancer Epidemiol, Vol.43, PP.71-9, 2014.

[2] P.Quirke, R.Steele, J.Monson, Effect of the plane of surgery achieved on local recurrence in patients with operable rectal cancer: a prospective study using data from the MRC CR07 and NCIC-CTG CO16 randomized clinical trial. Lancet, Vol.373, PP.821-8,2009.

[3] W.Hohenberger, K.Weber, K.Martzel, Standardized surgery for colonic cancer: complete mesocolic excision and central ligation - technical notes and outcome. Colorectal Dis, Vol.4, PP.35464, 2009.

[4] C.A.Bertelsen, A.U.Neuenschwander, J.E.Jansen, Disease-free survival after complete mesocolic excision compared with conventional colon cancer surgery: a retrospective, population-based study. Lancet Oncol, Vol.16, PP.161-8,2015.

[5] N.K.Kim, Y.W.Kim, Y.D.Han, M.S.Cho, H.Hur, and B.S Min, Complete mesocolic excision and central vascular ligation for colon cancer: Principle, anatomy, surgical technique, and outcomes. Surg Oncol, Vol.25, PP.252-62,2016.

[6] Hyeong, and Rok Kim ,"Complete Mesocolic Excision with Central Vascular Ligation in Comparison With Conventional Surgery for Patients with Colon Cancer - The Experiences at Two Centers, Vol.12, PP.272,2018

[7] I. Triantafyllidis, A.Bratkou, G.Paschalioris and C.h. Demertzidis ,Complete mesocolic excision with central vascular ligation compared to standard surgery for right colon cancer: A retrospective study of surgical and oncologic outcomes. European Society of Surgical Oncology, Vol.36, PP.80,2016.

[8] G.Galizia, E.Lieto, F.De Vita, Is complete mesocolic excision with central vascular ligation safe and effective in the surgical treatment of right-sided colon cancers? A prospective study. Int J Colorectal Dis, Vol.29, PP.89-97,2014.

[9] M.Abdelkhalek, A.Setit, F.Bianco, A.Belli,A.Denewer, and T.F.Youssef, Complete mesocolic excision with central vascular ligation in comparison with conventional surgery for patients with colon cancer - the experiences at two centers. Ann Coloproctol.; 34:180-6, 2018.

[10]Duck Hyoun Jeong,Hyuk Hur, and Seung Hyuk Baik,Laparoscopic right hemicolectomy with complete mesocolic excision provides acceptable perioperative outcomes but is lengthy —analysis of learning curves for a novice minimally invasive surgeon ,Canadian Journal of Surgery, Vol.57(5), PP.331-336, 2014.

[11] N.P.West, W.Hohenberger, K.Weber, A.Perrakis, P.J.Finan, and P.Quirke, Complete mesocolic excision with central vascular ligation produces an oncologically superior specimen compared with 
standard surgery for carcinoma of the colon. J Clin Oncol, Vol.28, PP. 272-278, 2010.

[12] G.L.Zhao and Y.Chen , Clinical efficacy of laparoscopic complete mesoreclalexcisionwith a medial-to-lateral approach for right colonic cancer. Chin J Dig Surg, Vol.13, PP.645-7, 2014.

[13] T.E.Le Voyer, E.R.Sigurdson, A.L.Hanlon, R.J.Mayer, J.S.Macdonald, Colon cancer survival is associated with increasing number of lymph nodes analyzed: a secondary survey of intergroup trial INT-0089. J Clin Onco, Vol.1 21, PP.29122919, 2013.

[14] G.J.Chang, M.A.Rodriguez-Bigas, J.M.Skibber, V.A.and Moyer,Lymph node evaluation and survival after curative resection of colon cancer: systematic review. J Natl Cancer Inst , Vol.99, PP.433-441, 2017.

[15] L.H.Iversen, A.Green, P.Ingeholm, Improved survival of colorectal cancer in Denmark during 2001-2012 - the efforts of several national initiatives. Acta Oncol (Madr), Vol.55(2), PP.1023, 2016.

[16] M.Spasojevic, B.V,Stimec, J.F.Fasel, 3D relations between right colon arteries and the superior mesenteric vein: a pre-liminary study with multi detector computed tomography. Surg Endosc; vol.25, PP.1883-6, 2011.
[17]H.Yada, K.Sawai, H.Taniguchi, Analysis of vascular anatomy and lymph node metastases warrants radical segmental bowel resection for colon cancer. World J Surg, Vol.21, PP.109-15, 1997.

[18] T.Shatari, M.Fujita, K.Nozawa, Vascular anatomy for right colon lymphadenectomy. Surg Radiol Anat, Vol.25, PP.86-8, 2003.

[19]I.J.Park, G-S.Choi, B.M.Kang,Lymph node metastasis patterns in right-sided colon cancers: is segmental resection of these tumors oncologically safe? Ann Surg Oncol, Vol.16, PP.1501-6, 2009.

[20] D.Ignjatovic, M.Spasojevic, and B.V.Stimec , Can the gastrocolic trunk of Henle serve as an anatomical landmark in laparo-scopic right colectomy? A postmortem anatomical study. Am J Surg, Vol.199, PP.249-54, 2010.

[21]Co. Ltd.Kanehara, Japanese Classification of Colorectal Carcinoma. Japanese Society for Cancer of the Colon and Rectum (JSCCR), Vol.32, PP.3806-12, 2009.

[22] C.A.Bertelsen, A.U.Neuenschwander, J.E.Jansen, A.Kirkegaard-Klitbo, J.R.Tenma, M.Wilhelmsen, L.A.Rasmussen, L.V.Jepsen, B.Kristensen, and I.Gögenur ,Short-term outcomes after complete mesocolic excision compared with 'conventional' colonic cancer surgery. Br J Surg, Vol.103, PP.581-9, 2016. 